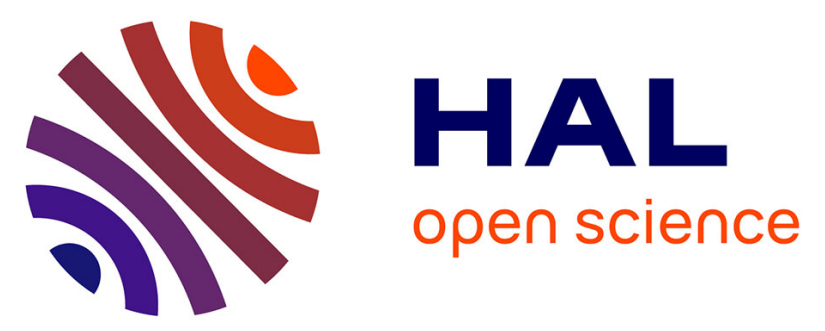

\title{
Berberine as a photosensitizing agent for antitumoral photodynamic therapy: Insights into its association to low density lipoproteins
}

Nathalia Luiza Andreazza, Christine Vevert-Bizet, Genevieve Bourg Heckly, Franck Sureau, Marcos José Salvador, Stéphanie Bonneau

\section{To cite this version:}

Nathalia Luiza Andreazza, Christine Vevert-Bizet, Genevieve Bourg Heckly, Franck Sureau, Marcos José Salvador, et al.. Berberine as a photosensitizing agent for antitumoral photodynamic therapy: Insights into its association to low density lipoproteins. International Journal of Pharmaceutics, 2016, 510, pp.240 - 249. 10.1016/j.ijpharm.2016.06.009 . hal-01399576

\section{HAL Id: hal-01399576 https://hal.science/hal-01399576}

Submitted on 19 Nov 2016

HAL is a multi-disciplinary open access archive for the deposit and dissemination of scientific research documents, whether they are published or not. The documents may come from teaching and research institutions in France or abroad, or from public or private research centers.
L'archive ouverte pluridisciplinaire HAL, est destinée au dépôt et à la diffusion de documents scientifiques de niveau recherche, publiés ou non, émanant des établissements d'enseignement et de recherche français ou étrangers, des laboratoires publics ou privés. 


\section{Berberine as a Photosensitizing Agent for Antitumoral Photodynamic Therapy: Insights into its Association to Low Density Lipoproteins.}

Nathalia Luiza Andreazza ${ }^{a}$, Christine Vevert-Bizet ${ }^{b}$, Geneviève Bourg-Heckly ${ }^{b}$, Franck Sureau ${ }^{b}$, Marcos José Salvador ${ }^{\mathrm{a}}$, Stephanie Bonneau ${ }^{\mathrm{b}}$.

anstituto de Biologia, Departamento de Biologia Vegetal, Universidade Estadual de Campinas (UNICAMP), 13083-970, Campinas, SP, Brasil.

borbonne Universités, UPMC Univ Paris 06, Centre National de la Recherche Scientifique (CNRS), Laboratoire Jean Perrin (UMR 8237), 4 place Jussieu, 75252 Paris cedex 05, France.

Corresponding author: nathilu@gmail.com and stephanie.boneau@upmc.fr

Permanent address:

Stéphanie Bonneau

Laboratoire Jean Perrin - UMR8237

Université Pierre et Marie Curie

Case courrier 114

4 place Jussieu

F-75005 Paris

France

Tel.: (33) 140279064

Fax: (33) 140274715

Keywords: Berberine, low-density lipoprotein, antitumor PDT, cellular uptake, subcellular localization. 


\section{ABSTRACT}

Recent years have seen a growing interest in Berberine, a phytochemical with multispectrum therapeutic activities, as anti-tumoral agent for photodynamic therapy (PDT). In this context, low density lipoproteins (LDL) play a key role in the delivery of the photosensitizer in tumor cells. We correlate the physicochemical parameters of the berberine association to LDL with the influence of LDL-delivery on its accumulation in a glioma cell line and on its photoinduced activity in view of antitumor PDT. Our results evidence an important binding of 400 berberine molecules per LDL. Changes in berberine and apoprotein fluorescence suggest different fixation types, involving various LDL compartments including the vicinity of the apoprotein. The berberine association to LDL does not affect their recognition by the specific $B / E$ receptors, of which over-expression increases the cellular uptake of LDL-preloaded berberine. Fluorescence microscopy evidences the mitochondrial labeling of the glioma model cells, with no significant modification upon LDL-delivery. Moreover, the cellular delivery of berberine by LDL increases its photocytotoxic effects on such cells. So, this research illustrates the potential of berberine as a photosensitizing agent for PDT, in particular due to their behavior towards LDL as plasma vehicles, and gives insights into its mechanisms of cell uptake.

\section{GRAPHICAL ABSTRACT}

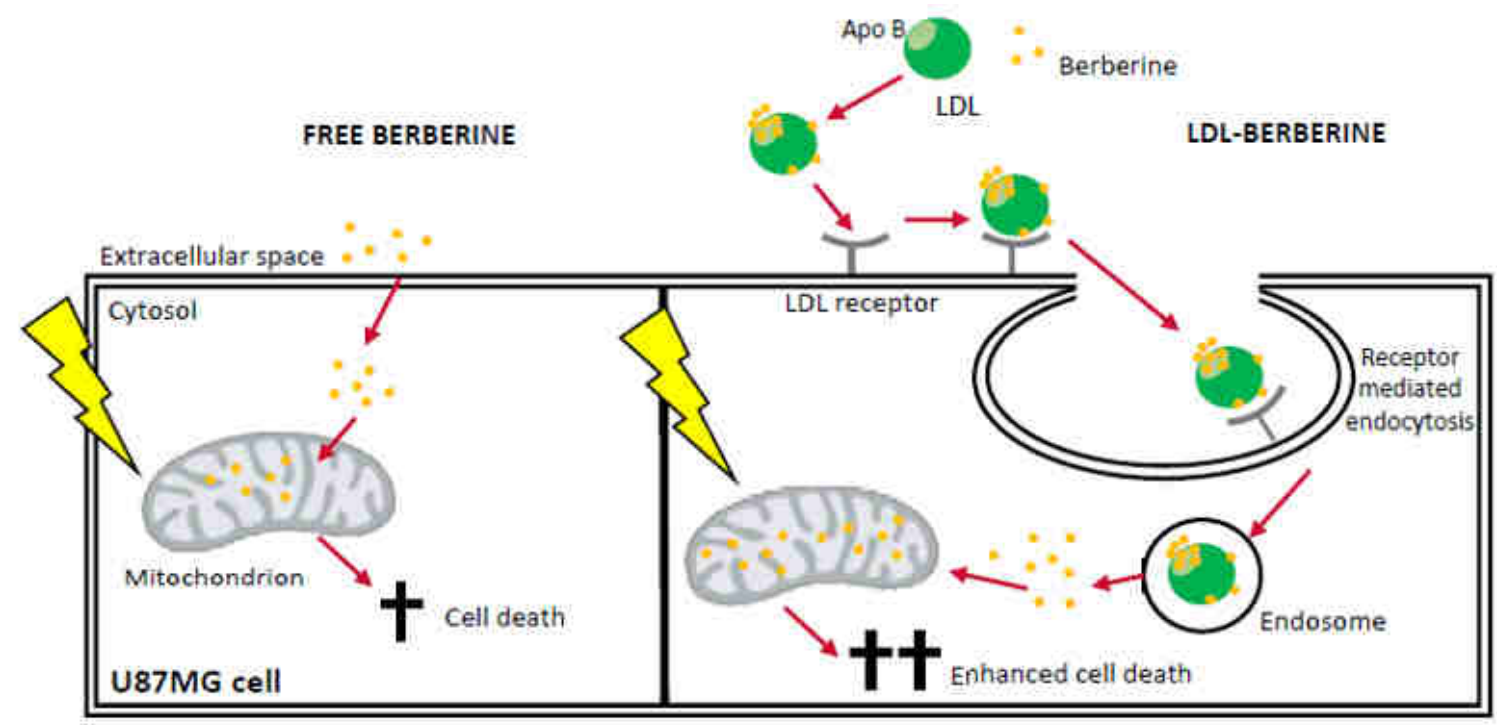




\section{1- INTRODUCTION}

Berberine (Figure S1) is an isoquinoline alkaloid present in species of Annonaceae and Ranunculaceae families. This natural compound is traditionally used in Chinese medicine to treat gastrointestinal diseases (Remppis et al., 2010) and has multiple pharmacological activities including anti-diabetic, anti-inflammatory, anti-malarial, anti-microbial, anti-cancer and antioxidative (Gu et al., 2010; Kuo et al., 2004; Küpeli et al., 2002; Sarna et al., 2010; Vuddanda et al., 2010; Wang et al., 2009; Wu et al., 2010; Yin et al., 2008). In addition, berberine has been confirmed to penetrate the blood-brain barrier and exhibits beneficial effects in the central nervous system (Kulkarni and Dhir, 2010; Lin et al., 2013).

In the last ten years, berberine has been more extensively studied as photosensitizing agent for photodynamic therapy (PDT) (L. Cheng et al., 2009; L.-L. Cheng et al., 2009; Inbaraj et al., 2001; Jantová et al., 2006). PDT is an attractive alternative antitumor approach, due to both its specificity and its ability to be combined with photodynamic diagnosis imaging (PDD), which presents a great interest largely highlighted in the recent years (Jayaram et al., 2016; Silva et al., 2013). The concomitant actions of a photo-activable substance, so-called photosensitizer (PS), light and oxygen is the basic principle of this approach (Castano et al., 2004). The search for efficient sensitizers with high specificity has provided potential impetus because of the wide range of applications of the antitumor PDT (Acherar et al., 2015; Pariser et al., 2003; Peng et al., 2009), that is promising for new applications such as in urology (Azzouzi et al., 2013), pneumonology (Du et al., 2010) or neurosurgery, where encouraging results have been reported concerning the use of interstitial photodynamic therapy as treatment of front-line nonresectable or recurrent glioblastoma (Beck et al., 2007).

Photodynamic therapy involves in general a systemic administration of the photosensitizer to the patient, followed by the light irradiation of the targeted zone. As the photo-induced cytotoxic species have very short lifetimes and subsequently limited diffusions (Kerdous et al., 2011; Kuimova et al., 2009; Moan and Berg, 1991), primary damages affect the subcellular structures labeled by the photosensitizer. Its intracellular distribution is then a major determinant of the PDT efficacy, although the overall response to these primary damages is complex (Piette et al., 2003). As a matter of fact, note that the subcellular localization of photosensitizers is well correlated with their global photocytotoxixity (Woodburn et al., 1992) and the mechanism of cell death (Hsieh et al., 2003; Kessel et al., 1997). The relative photo-efficiency and the subcellular localization of photosensitizers depend on their structure, in particular on their hydrophobicity and charges (Bonneau et al., 2007; Boyle and Dolphin, 1996; Hsieh et al., 2010).

Among the processes that could account for the retention of photosensitizers by tumor tissues, an important one is related to their hydrophobicity and is specific to these proliferating targets. In tumor cells, indeed, the increase of the cholesterol catabolism results in an over-expression of low-density lipoproteins' receptors (B/E receptors). Moreover, as lipophilic drugs, the photosensitizers present a high affinity for low-density lipoproteins (LDL) (Bonneau and Vever-Bizet, 2008; Huntosova et al., 2010). Hence, as previously shown for different lipophilic and amphiphilic photosensitizers, LDL can act as targeted nano-carriers enhancing the pharmacological efficacy of these agents (Bonneau et al., 2004; Huntosova et al., 2010; Mojzisova et al., 2007). Besides, the LDL ability to be specifically transcytozed across the blood-brain barrier (Candela et al., 2008) must be taken into consideration regarding the encouraging promises of PDT in neurosurgery. 
In this context, the first aim of this study is to describe the physicochemical properties of the berberine interaction with LDL, using spectroscopic methods. Different classes of binding have been identified and characterized by monitoring both the fluorescence of LDL and that of berberine. We have then evaluated the effect of this interaction on the drug behavior toward human primary glioblastoma cell line. The cellular uptake and subcellular localization in cell models with standard (normal) and enhanced number of LDL receptors were analyzed and, finally, the photosensitizing potential of both free and LDL-associated berberine determined through lipid peroxidation and cell viability assays.

\section{2- MATERIAL AND METHODS}

\section{1-Chemicals.}

Berberine (BBR, 99\% purity), dimethyl sulfoxide (DMSO, 99.9\%) and Human Serum Albumin (HSA), essentially fatty acid free, were purchased from Sigma-Aldrich (Saint Louis, Missouri, USA). The chlorin e6 (Ce6) was purchased from Frontier Scientific (Logan UT, USA). Ethanol (99.8\%) was purchased from Merck (Darmstadt, Germany). Phosphate buffer Saline (PBS) and Hank's balanced salt solution (HBSS), both at pH 7.2 and all the other cell culture reagents were purchased from GIBCO-Invitrogen (Cergy Pontoise, France), except the Ultroser $\mathrm{G}$ obtained from BioSepra (SA-Part of Pall Corporation, France). Human low density lipoproteins (LDL, purity $>95 \%$ ) were purchased from Calbiochem (Nottingham, England) and the fluorescent probes Mitotracker ${ }^{\circledast}$ Red and Lysotracker ${ }^{\circledast}$ Red from Molecular Probes (Eugene, Oregon, USA). The reagents for all biochemical analyses were purchased from Sigma-Aldrich (Saint Louis, Missouri, USA). The storage proceedings of all these chemicals, reagents and substances were made according to manufacturer's information. The photosensitizer solutions were handled in dark to avoid any photobleaching.

\section{2- Spectroscopic studies.}

The absorption spectra were measured with an UVIKON 923 double beam UV/VIS spectrophotometer (BioTEK Kontron Instruments). Fluorescence emission spectra were recorded using an AMINCO-Bowman 2 spectrofluorimeter (Edison, NJ) equipped with a xenon arc lamp. Solutions were in PBS pH 7.2, otherwise further information is given. Recording was generally started 2 min after solution's preparation. Data thus obtained were analyzed as briefly described in the subsequent paragraph.

\section{3- Analysis of the interaction of $L D L$ with berberine}

Partition experiments of berberine between LDL and aqueous solution were performed at equilibrium with various $L D L$ concentrations $\left(0\right.$ to $\left.10^{-8} \mathrm{M}\right)$. The global binding constant, $\mathrm{K}_{\mathrm{LDL}}$ was derived from the changes in the berberine fluorescence at $544 \mathrm{~nm}$ (corresponding to the maximum of the fluorescence emission of berberine within LDL). We used the previously derived relationship (Kuzelova and Brault, 1994):

$F-F_{0}=\frac{\left(F_{\infty}-F_{0}\right) \times \mathrm{K}_{\mathrm{LDL}} \times[L D L]}{1+\mathrm{K}_{\mathrm{LDL}} \times[L D L]}$

where $F_{0}, F_{\infty}$ and $F$ are the fluorescence intensities of berberine corresponding to zero, total and intermediate association of the berberine to LDL, respectively.

According to our experimental results, the berberine association to LDL was described as involving two class of fixations. The first class, denoted class $P$, corresponds to the binding of 
berberine molecules evidenced by the quenching of the fluorescence of the apoprotein B100 of LDL. From this binding-induced changes in LDL-fluorescence properties, we derived the association parameters with the previously described method according with (Halfman and Nishida, 1972) and (Bonneau et al., 2004, 2002) as follows.

By definition, at a given LDL concentration:

$\mathrm{P}_{\mathrm{F}}=\mathrm{LDL}\left(\mathrm{P}_{\mathrm{T}} / \mathrm{LDL}-\mathrm{v}\right)$

where $\mathrm{P}_{\mathrm{F}}$ and $\mathrm{P}_{\mathrm{T}}$ are respectively the concentrations of free berberine in the aqueous solution and the total berberine concentration, $v$ the number of berberine molecules bound per lipoprotein, and LDL the concentration of the latter. The Nishida method is based on the existence of pairs of $P_{T}$ and $L D L$ concentrations yielding the same value of $v$. Then, for two pairs noted $a$ and $b$ it follows from equation (2):

$v=\left[\mathrm{P}_{\mathrm{Ta}} / \mathrm{LDL}_{\mathrm{a}}-\left(\mathrm{LDL}_{\mathrm{b}} / \mathrm{LDL}_{\mathrm{a}}\right) *\left(\mathrm{P}_{\mathrm{Tb}} / \mathrm{LDL}_{\mathrm{b}}\right)\right] /\left(1-\mathrm{LDL}_{\mathrm{b}} / \mathrm{LDL}_{\mathrm{a}}\right)$
$\mathrm{P}_{\mathrm{F}}=\left[\mathrm{LDL}_{\mathrm{a}} \mathrm{LDL}_{\mathrm{b}} /\left(\mathrm{LDL}_{\mathrm{a}}-\mathrm{LDL}_{\mathrm{b}}\right)\right]\left(\mathrm{P}_{\mathrm{Tb}} / \mathrm{LDL}_{\mathrm{b}}-\mathrm{P}_{\mathrm{Ta}} / \mathrm{LDL}_{\mathrm{b}}\right)$

Assuming that the interaction of the same number of molecules per LDL (the same $v$ value) involves the same changes in LDL fluorescence properties, these two pairs correspond to the same $\Delta(F / F 0)$ where $F$ and $F 0$ are the fluorescence intensities of LDL in presence and in absence of berberine. The quenching efficiency was thus measured, for two concentrations of LDL ( 2 and $6 \times 10^{-8} \mathrm{M}$ ), as a function of the total berberine concentration. Pairs of $\mathrm{P}_{\mathrm{T}}$ and LDL concentrations yielding the same value of F/FO were selected, and the values of $V$ and $P_{F}$ were derived according to equation (3) and (4). The results were plotted according to the Scatchard method.

The binding of additional berberine molecules to LDL, which do not change the intrinsic fluorescence of $L D L$, correspond to the second class of fixation and are denoted class $L$.

\section{4- Cell culture and experimental series preparation.}

Cells from the human primary glioblastoma cell line U87-MG were obtained from the American Type Culture Collection (Manassas, VA, USA) and routinely grown as monolayer at $37^{\circ} \mathrm{C}$ in Dulbecco's modified Eagle's medium (DMEM) supplemented with $10 \%$ fetal bovine serum (FBS) and $100 \mathrm{U} / \mathrm{ml}$ of penicillin and $100 \mu \mathrm{g} / \mathrm{ml}$ of streptomycin, under atmosphere controlled at $100 \%$ of relative humidity and $5 \% \mathrm{CO}_{2}$. The cells were passed every 4 days and used between the $10^{\text {th }}$ and the $19^{\text {th }}$ passages. Experimental series are defined as follows: cells are incubated with berberine (LDL- series) or with the LDL-Berberine complex (LDL+ series) in $\mathrm{HBSS}$ at $37^{\circ} \mathrm{C}$. For the experiments on cells with over-expression of LDL receptors ( $\mathrm{R}+$ series), FBS was replaced within the growing medium by $2 \%$ Ultroser $\mathrm{G}$ one week before experiments (Mojzisova et al., 2007). For all the series (R-/LDL-, R-/LDL+, R+/LDL- and $\mathrm{R}+/ \mathrm{LDL}+$ ), the berberine is used at $1 \times 10^{-6} \mathrm{M}$ and $\mathrm{LDL}$ at $1 \times 10^{-8} \mathrm{M}$ LDL (BBR/LDL=100). A fifth series, used as control, involved experiments carried out by using the same protocol but without any photosensitizer.

\section{5- Microscopy.}

Fluorescence images were obtained using an inverted microscope (Nikon Eclipse TE300) equipped with a high aperture phase oil objective (CFI Plan apochromat DM 60x N.A. 1.4, Nikon, France). The excitation light was provided by a $130 \mathrm{~W}$ mercury lamp illuminator (Intensilight, Nikon). Illumination wavelengths were isolated by band-pass filters $(355 \pm 25 \mathrm{~nm}$ for berberine, $570 \pm 25 \mathrm{~nm}$ for the used organelles probes) and intensity was optimized by 
neutral density filters (ND4 and ND8). The fluorescence emission was collected through band-pass filters ( $535 \pm 25 \mathrm{~nm}$ for berberine and $610 \pm 10 \mathrm{~nm}$ for the organelles probes). The images were acquired with a camera Neo sCMOS (Andor Technology). The acquisition, processing and image analysis were performed with NIS-Element provided by Nikon and Image J (open source software, http://rsb.info.nih.gov/ij / index.html).

\section{6- Berberine uptake by U87-MG cells.}

After incubation for $15,30,60,120$ and 180 minutes, to quantify the uptake by extraction, the cells seeded in Petri dishes were used at $70 \%$ confluence. After incubation and washing, they were scrapped in $900 \mu \mathrm{l} \mathrm{H}_{2} \mathrm{O}$ and $100 \mu \mathrm{l}$ of $3 \%$ Triton X100 solution. Then, $100 \mu \mathrm{l}$ of the disrupted cell solution were saved for the protein determination by Lowry's method. The $900 \mu \mathrm{l}$ of remaining solution was used for the fluorimetric measurement of the berberine concentrations. Data, expressed as $\mu$ mole of berberine per gram of protein, are means $( \pm S D)$ of triplicates. Alternatively, after one hour of incubation, cells were observed under fluorescence microscope.

\section{7- Subcellular localization of berberine within U87-MG cells.}

After one hour of incubation, the cells were washed twice with HBSS and then incubated with Mitotracker ${ }^{\oplus}$ Red or Lysotracker ${ }^{\oplus}$ Red $(200$ nM) for 30 minutes. The Pearson Coefficient (CP) was determined using Image J.

\section{8- Irradiation set-up.}

Irradiation was carried out using a $300 \mathrm{~W}$ xenon lamp. A $410 \pm 10 \mathrm{~nm}$ band-pass filter (Andover Corporation) was used to select the irradiation band. As positive control, we used samples incubated with chlorin e6, a well known photosensitizer (Mojzisova et al., 2009, 2007), irradiated through a $\mathrm{K} 65$ Balzer band-pass filter $(660 \pm 15 \mathrm{~nm})$. The light beam had a diameter of about $50 \mathrm{~mm}$, allowing the irradiation of a $30 \mathrm{~mm}$ diameter plate at a time. The irradiance uniformity was controlled by scanning the zone with a power meter. Variation of intensity observed was less than $5 \%$. The liquid height in the wells was only $0.5 \mathrm{~cm}$ to prevent any light attenuation. For the light-dose dependent studies, the samples were irradiated at light fluencies of $10,25,50$ and $100 \mathrm{~J} / \mathrm{cm}^{2}\left(65 \pm 0.5 \mathrm{~mW} / \mathrm{cm}^{2}\right.$ for $2.5,6.5,13$ and $23 \mathrm{~min}$, respectively).

\section{9- Evaluation of the photo-induced effects on cells.}

Lipid peroxidation within irradiated cells was evaluated by TBARS assay, both on cellular medium culture and cell extract. The reagent solution was added to the same volume of the sample of interest. The mixture was heated in a water bath at $80^{\circ} \mathrm{C}$ for $15 \mathrm{~min}$, butanol was then added, and the organic phase was analyzed by spectrofluorimetry. Spectra were recorded between 525 and $800 \mathrm{~nm}$ with an excitation at $415 \mathrm{~nm}$. Data are means ( \pm SD) of triplicates in three different assays.

The viability of irradiated cells was assessed by colorimetric MTT assays. Cells were plated into 96 -well plates at a density of $5 \times 10^{4}$ cells/well one day before experiments. After treatment and washing twice, MTT solution $(5 \mathrm{mg} / \mathrm{ml})$ and medium were introduced. After incubation for $4 \mathrm{~h}$, the formed formazan crystals were dissolved in dimethyl sulfoxide and the absorbance intensity measured by a microplate reader (Synergy 2, BioTek Instruments, USA). Each sample was evaluated in triplicate and the experiment was repeated three times. Percentage of cell proliferation was calculated as the ratio between the absorbance at 570 
$\mathrm{nm}$ of the sample and that of the control. Data are means $( \pm S D)$ of triplicates in three different essays.

\subsection{0- Statistical analysis.}

All data are means $( \pm S D)$ of at least three independent replicates and were processed and represented using GraphPad Prism software (GraphPad Software, version 5.00, San Diego, CA). Comparisons among the different series of each experiment were performed by analysis of variance and Tukey-Kramer range test. Correlations were analyzed with Pearson correlation analysis. $P$ values $<0.05$ were considered significant. Letters indicate if the compared samples are statistically different (represented by different letters) or not (represented by equal letters) within the evaluated group.

\section{3- RESULTS AND DISCUSSION}

\section{1- Spectroscopic properties of berberine.}

The berberine absorption and fluorescence spectra were recorded at different concentrations in solvents with different physicochemical properties (Figure S1). The absorption spectra exhibit only small changes depending on the solvent. The absorption bands are slightly blue-shifted $(17 \pm 2 \mathrm{~nm})$ with increasing solvent polarity. The fluorescence is more sensitive to the environment. In organic solvents, the maximum intensity is halved and the corresponding wavelength red-shifted with polarity decrease. In PBS, berberine exhibits a drastic fluorescence decrease ( $\max 544 \mathrm{~nm}$ ). Our observations (Table S1) are in accordance with previous ones (L. Cheng et al., 2009; L.-L. Cheng et al., 2009; Jantová et al., 2006).

\section{2- The berberine interaction with LDL.}

The interaction between berberine and LDL was primarily evidenced by the changes of berberine fluorescence in presence of LDL (Figure 1). The intensity is strongly enhanced and shifted from 544 to $510 \mathrm{~nm}$, with a behavior similar to that observed in organic solvents. Moreover, the UV-Vis absorption spectrum of LDL in complexed form (subtraction of the berberine absorption to that of the mixture) cannot be superposed with that of naive ones, suggesting an association of both species. The alkaloid binding has then been studied by assessing induced changes in both the berberine fluorescence and the LDL one.
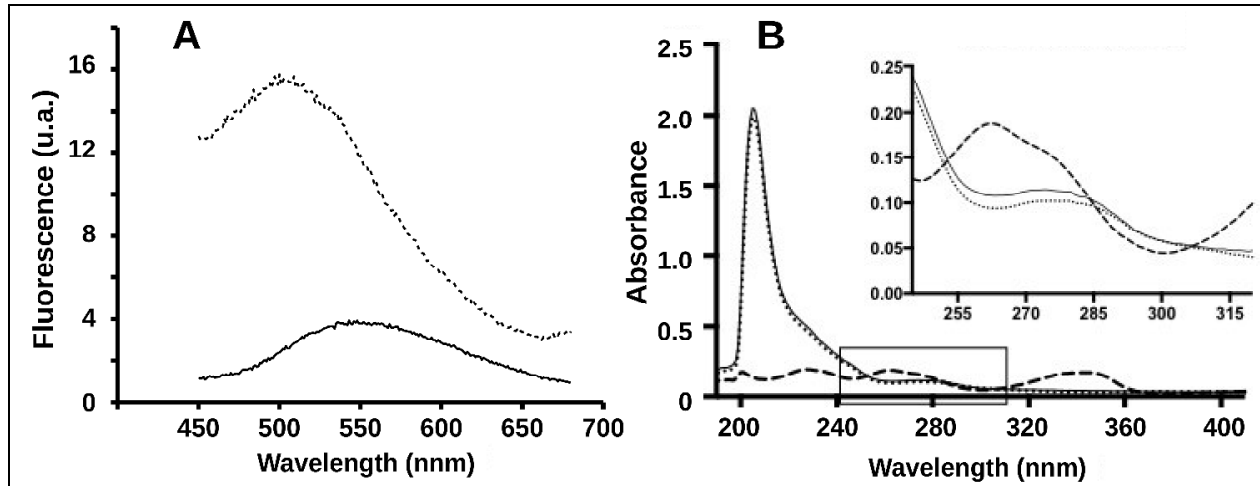

Figure 1: Spectra of berberine with LDL. (A) Berberine fluorescence in PBS (solid line) and in presence of LDL (dashed line). Excitation $350 \mathrm{~nm}$. (B) Absorption spectrum of naive LDL (short dash), of berberine (long dash) and difference absorption spectrum between the $\mathrm{LDL} /$ Berberine complex and that of berberine (solid line). $[\mathrm{LDL}]=6 \times 10^{-8} \mathrm{M}$ and $[\mathrm{BBR}]=3 \times 10^{-6}$ M. (Insert) Focus on the spectra from 240 to $360 \mathrm{~nm}$. 
First, fluorescence measurements were performed by adding increasing amounts of LDL to berberine solution $\left(10^{-6} \mathrm{M}\right)$ and the berberine fluorescence was simultaneously followed (Figure 2). The plot of the fluorescence intensity presents a plateau, of which the intercept with the initial slope corresponds to an LDL concentration of $2.5 \times 10^{-9} \mathrm{M}$. The corresponding ratio of concentrations between bound berberine and LDL indicates that each lipoprotein could bind about 400 berberine molecules at best. Analysis according to equilibrium equation (1) gives a global association constant ( $\left.\mathrm{K}_{\mathrm{LDL}}\right)$ of $(1.76 \pm 0.2) \times 10^{8} \mathrm{M}^{-1}$. Duplication of experiments with other berberine and LDL concentrations led to consistent values.

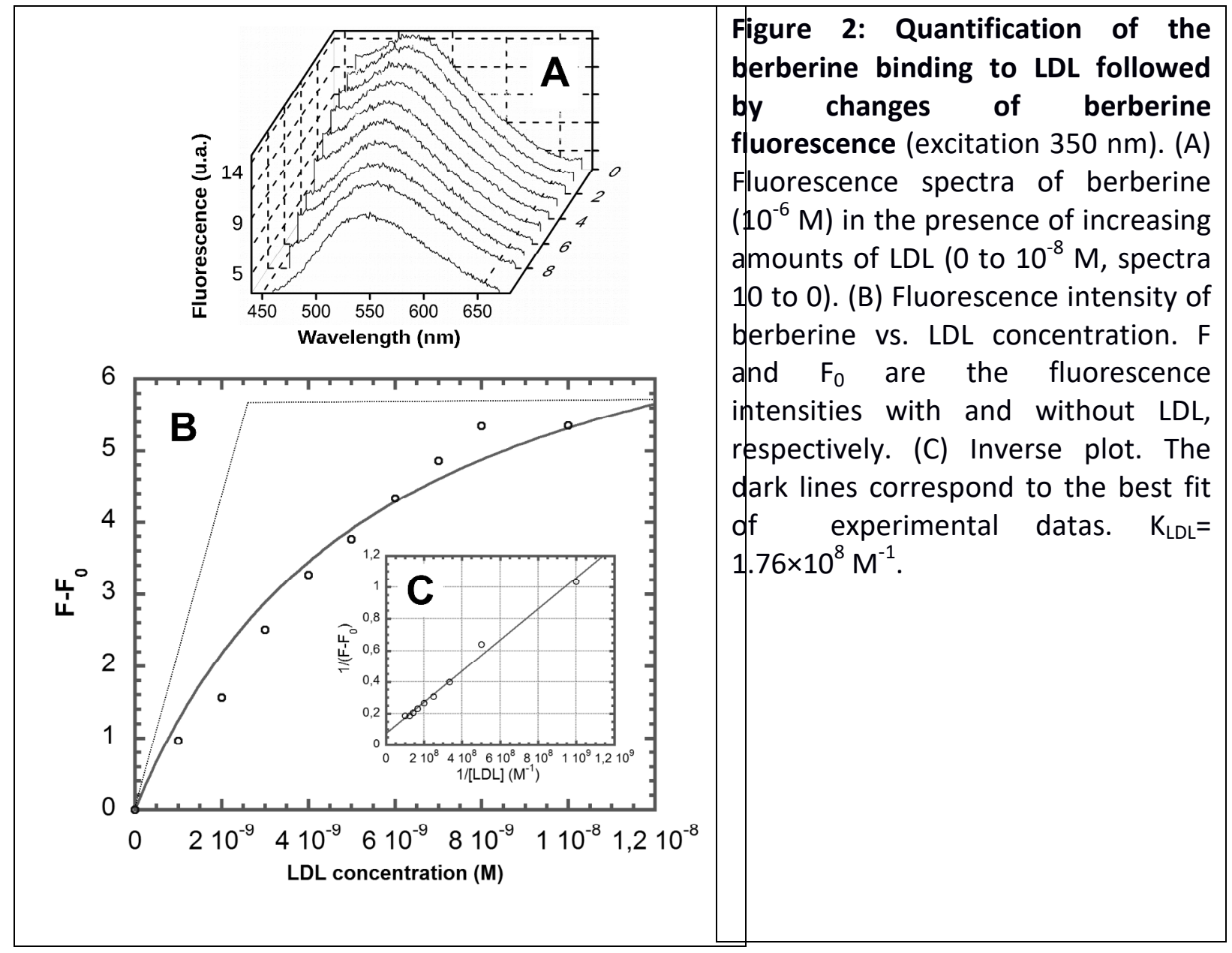

In a second step, the binding characterization was apprehended by following the changes of the LDL fluorescence induced upon berberine addition. Indeed, under excitation at $280 \mathrm{~nm}$, the LDL display an intrinsic fluorescence emission band near $330 \mathrm{~nm}$, due to the tryptophan residues of the apoprotein B100. The significant overlap of this band with the berberine absorption spectrum allows a Förster Resonance Energy Transfer (FRET) to the alkaloid. The Förster distance has been estimated to be 3,1 nm (Hu et al., 2010) for a related berberine/tryptophan couple. The binding of berberine molecules at the direct vicinity of the apoprotein (to the apoprotein or at the frontier between protein and lipids) may then be assessed by FRET. Such associations will be denoted class $P$ fixation.

The FRET efficiency is experimentally evidenced by the quenching of the aproprotein fluorescence by the binding of berberine, in a concentration-dependent manner (Figure 3A) with a concomitant fluorescence increase around $500 \mathrm{~nm}$. The significant fluorescence quenching observed even for relatively low amounts of alkaloid indicates the presence of high-affinity class $P$ sites. The blue-shift of the LDL fluorescence suggests an increased 
hydrophobicity of the environment of the non-quenched tryptophan residues. For low degree of berberine binding, a linear stoichiometric relationship between the fluorescence intensity and the degree of binding was observed. The Stern-Volmer constant has been calculated to be $(1.11 \pm 0.05) \times 10^{5} \mathrm{M}^{-1}$ (Figure 3B). For higher degree of berberine binding, the relationship depends upon the protein concentration (Figure $3 \mathbf{C}$ ). Indeed, for each site, the FRET efficiency depends on the distance and relative orientation of the donnor-acceptor couple, and its dependency on the number of berberines bound per LDL is not linear. Hence, the binding related to this quenching has been characterized using the method developed by Halfman and Nishida (Halfman and Nishida, 1972). This approach is based on the existence of pairs of berberine and LDL concentrations yielding to the same number of berberine molecules bound per lipoprotein and a unique quenching efficiency, as described elsewhere (Bonneau et al., 2002). According to calculations briefly described in the section 2.3, two sets of sites appear to adequately describe this binding process (Figure 3D). The first set, denoted class $P$ type 1 , involves 180 sites of which intrinsic affinity, $K_{\mathrm{P} 1 \text {, }}$ is $8.6 \times 10^{5} \mathrm{M}^{-1}$. The second set of class $P$ type 2 fixations is identified as 40 sites of intrinsic affinity of $2.5 \times 10^{5} \mathrm{M}^{-}$ 1 . The total association constant for these two types of class $P$ sites, i.e. identified by the induced changes in LDL fluorescence and thus involving localizations at the vicinity of the apoprotein, is then $1.65 \times 10^{8} \mathrm{M}^{-1}$. The precise localization of these two types of site will be discussed with respect to the LDL recognition by their cellular receptors. Note that the apoprotein is organized around the LDL-particle and lies in a hydrophobic environment offering possible binding areas for berberine molecules.
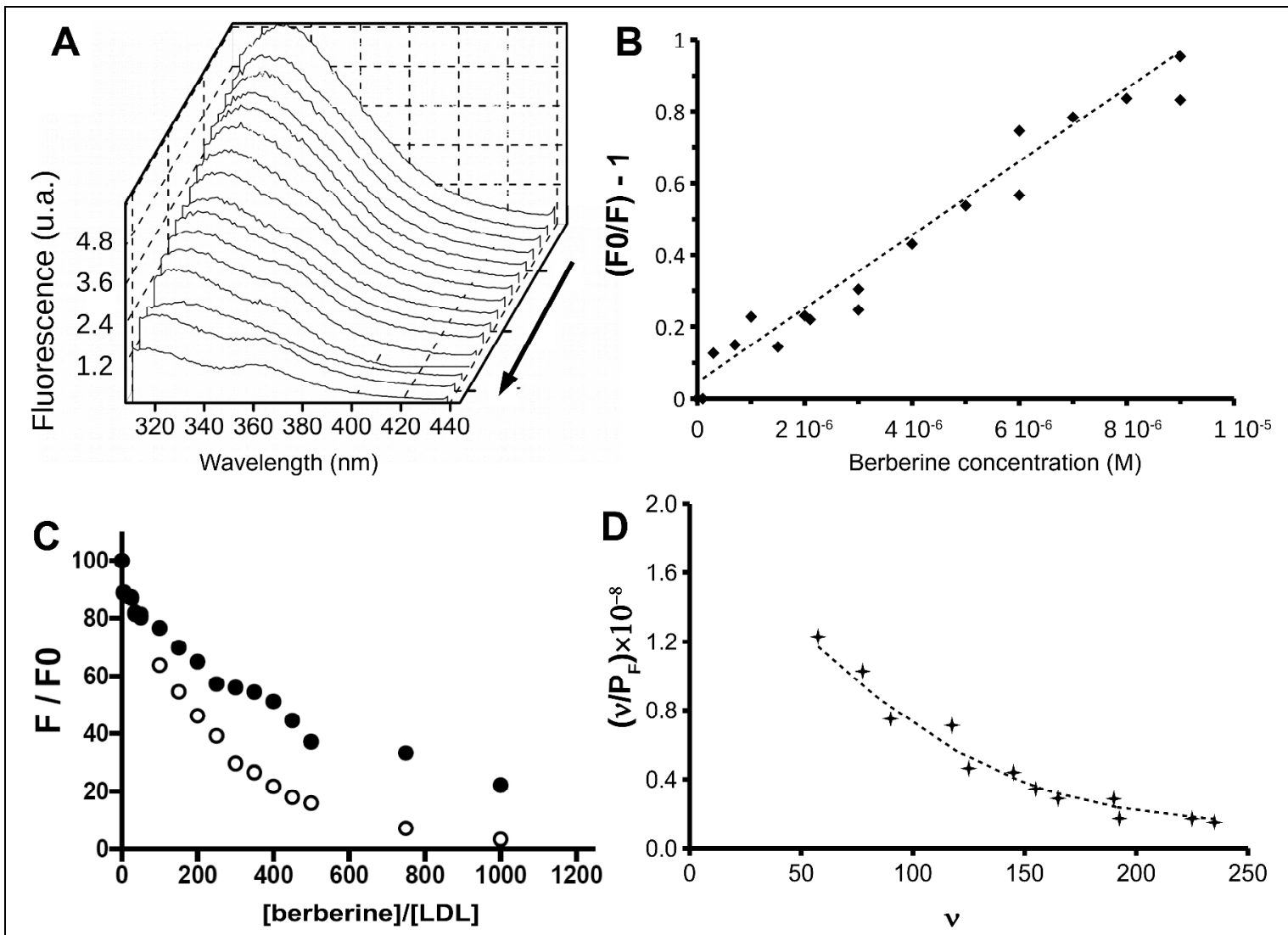

Figure 3: Quantification of the berberine binding to LDL followed by changes of LDL fluorescence - Class P fixation. (excitation $280 \mathrm{~nm}$ ) (A) Quenching of LDL fluorescence $\left([L D L]=2 \times 10^{-8} \mathrm{M}\right)$ upon addition of increasing amounts of berberine. [berberine]/[LDL] $=0$ to 1000 in the arrow direction. (B) Stern-Volmer plot. (C) Relative fluorescence intensity at 330 
$\mathrm{nm}$ as a function of [berberine]/[LDL]. $[\mathrm{LDL}]=2 \times 10^{-8} \mathrm{M}$ (black circles) or $6 \times 10^{-8} \mathrm{M}$ (white circles). (D) Scatchard plot obtained from computed data (Halfman and Nishida, 1972).

The first described study, in which the berberine fluorescence was followed, showed that the binding capacity exceeds that of the 220 class $P$ sites identified at the vicinity of the apoprotein. Other LDL compartments including the outer phospholipid layer and the inner core should thus be involved in the binding for around 180 sites - denoted class $L$ fixation and a lower association constant, $K_{L}$, of about $1.1 \times 10^{7} \mathrm{M}^{-1}$. Nevertheless, when LDL concentrations are large enough to bind all the berberine molecules, the fluorescence spectra of the latter is typical of hydrophobic environments, regardless of the [berberine]/[LDL] ratio. This indicates that the characteristics of the berberine bound to the lipoproteins in the different locations are almost similar. All the constants are summarized in the Table 1.

\begin{tabular}{|c|c|c|c|c|c|}
\hline \multicolumn{6}{|c|}{$\mathrm{K}_{\mathrm{LDL}}$} \\
\hline \multicolumn{6}{|c|}{$1.76 \times 10^{8} \mathrm{M}^{-1(2)}$} \\
\hline \multicolumn{4}{|c|}{$K_{P}\left(=K_{P 1}+K_{P 2}\right)$} & \multicolumn{2}{|r|}{$\mathrm{K}_{\mathrm{L}}$} \\
\hline \multicolumn{4}{|c|}{$1.65 \times 10^{8} \mathrm{M}^{-1}\left(1.55 \times 10^{8} \mathrm{M}^{-1}+1.00 \times 10^{7} \mathrm{M}^{-1}\right)^{(1)}$} & \multicolumn{2}{|c|}{$1.10 \times 10^{7} \mathrm{M}^{-1(1,2)}$} \\
\hline $\mathrm{n}_{\mathrm{P} 1}$ & $K_{\text {P1i }}$ & $\mathrm{n}_{\mathrm{P2}}$ & $\mathrm{K}_{\mathbf{P} 2 \mathrm{i}}$ & $\mathrm{n}_{\mathrm{L}}$ & $\mathrm{K}_{\mathrm{Li}}$ \\
\hline $180^{(1)}$ & $8.6 \times 10^{5} \mathrm{M}^{-1(1)}$ & $40^{(1)}$ & $2.5 \times 10^{5} \mathrm{M}^{-1(1)}$ & $\sim 180^{(1,2)}$ & $\sim 6 \times 10^{4} \mathrm{M}^{-1(1,2)}$ \\
\hline
\end{tabular}

Table 1. Values of the equilibrium constants of the association of the berberine with the low density lipoproteins. ${ }^{(1)}$ Values calculated from the data obtained by following the changes in intrinsic LDL fluorescence. ${ }^{(2)}$ Values calculated from data obtained by following the berberine fluorescence.

\section{3- Berberine uptake by human primary glioblastoma cell line.}

After incubation of cells with berberine solution, the fluorescence of the alkaloid is found to present a coarse granular filamentous staining (Figure 4), suggesting mitochondria involvement. The berberine distribution and uptake seem not to be modified upon vectorization by the lipoproteins nor by the over-expression of the LDL-receptors. To decipher the behavior of the berberine toward glioma model cells, four series of experiments have been performed, with free or LDL-preloaded berberine (LDL- and LDL+ series), on cells over-expressing or not the specific $L D L$ receptors ( $R+$ and $R-$ series, see the methods section).

The uptake has been quantified by extraction. For all experiment series, the maximum of uptake appears after 60-120 minutes of incubation. All the kinetics are very similar, in good agreement with our preliminary microscopy observations, except for $R+/ L D L+$ series. For the three others, an important decrease of the accumulated berberine takes place after 60 minutes. For the $\mathrm{R}+/ \mathrm{LDL}+$ series, the maximum accumulation appears after $120 \mathrm{~min}$ and is still almost stable after 180 min. However, similar trends of reduction in the intracellular berberine amount can always be detected. For all series, this may indicate a possible early process of alkaloid metabolism which could, in the PDT context, be beneficial to avoid prolonged periods of light sensitivity. 


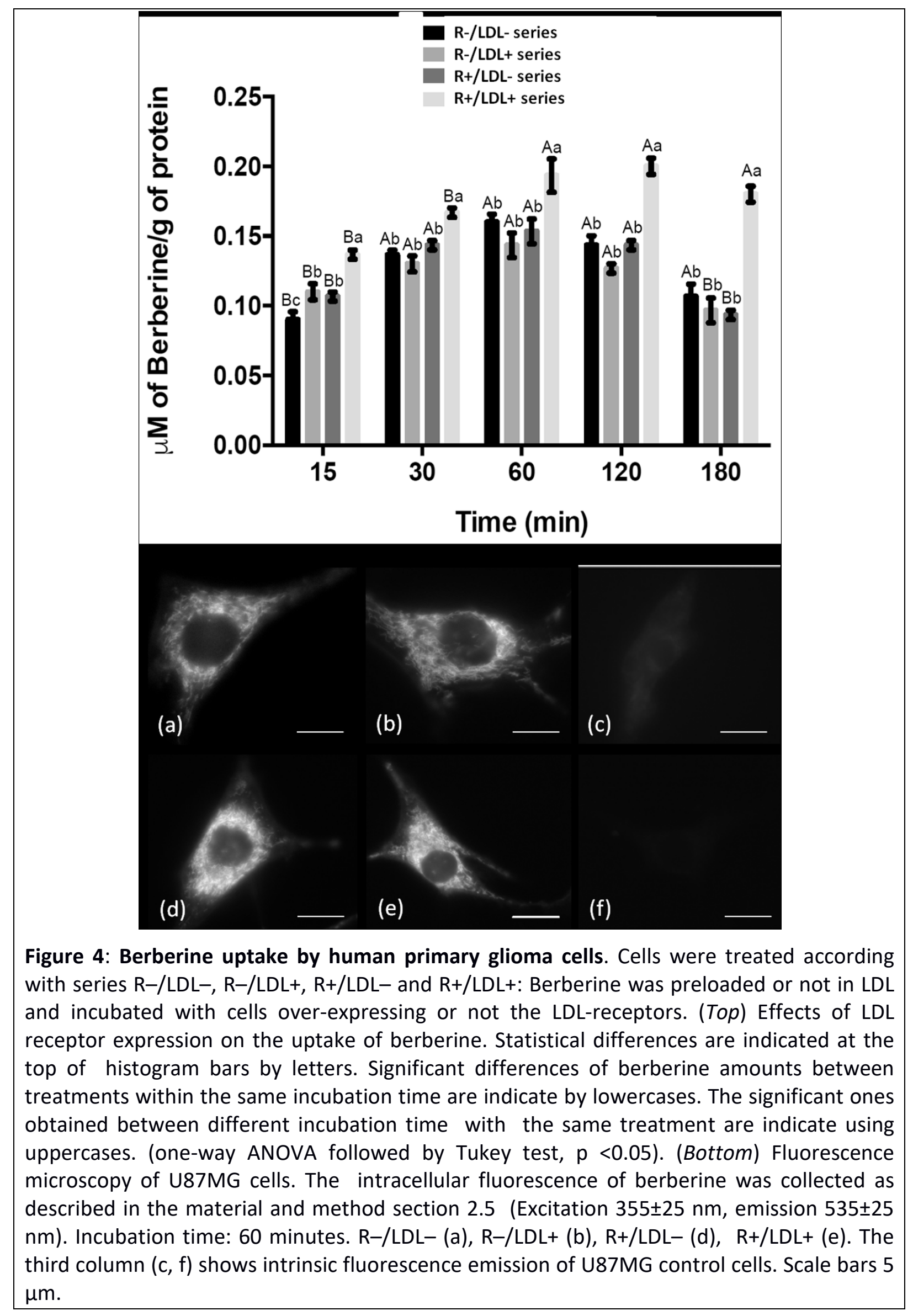




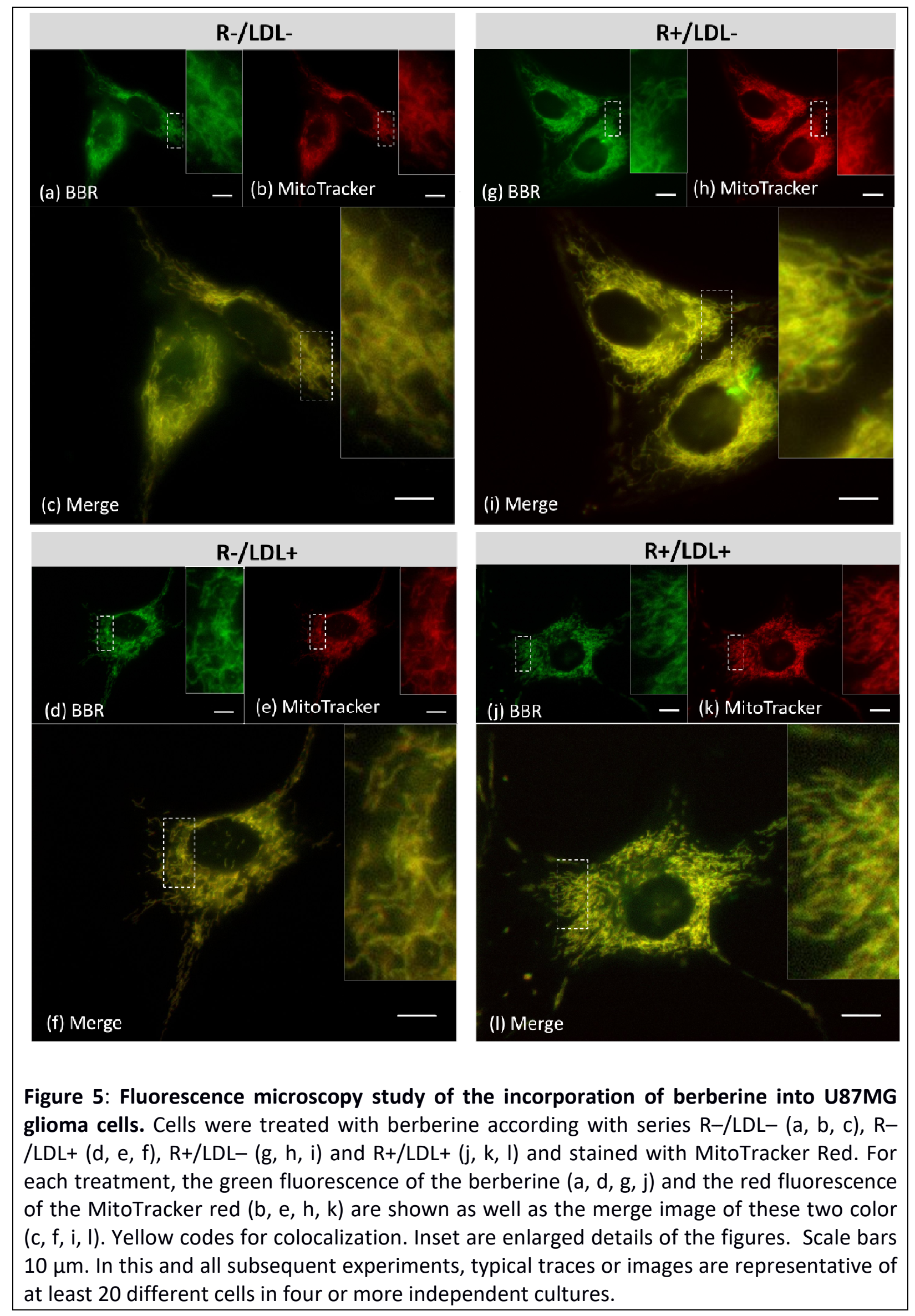


Moreover, for the $\mathrm{R}+/ \mathrm{LDL}+$ series, the intracellular amount of berberine is higher than those observed for all other series (Figure 4). Thereby, the stimulation of LDL receptors expression actually ensures an increase of the cellular uptake of the LDL-preloaded berberine up to $29 \%$ after $120 \mathrm{~min}$ of incubation. This indicates that the recognition of the LDL by cells is unaltered upon the binding of berberine and support the hypothesis that berberine rather interacts at the boundary between the apoprotein and the lipid phase of the LDL than at the apoprotein surface. To support this idea, comparison can be made on the basis of the number of phospholipids per LDL. The affinity constant per lipid is calculated to be $2.2 \times 10^{5}$ $\mathrm{M}^{-1}$, in good agreement with that of other photosensitizers (Bonneau et al., 2002).

\section{4- Subcellular localization of berberine within U87-MG cells.}

Analysis of the colocalization studies of the intracellular berberine with Mitotracker Red clearly demonstrates the mitochondrial localization of the berberine in the four series of experiments (Figure 5), in good agreement with previous studies (Inbaraj et al., 2001; Lakowicz, 2006; Mikes and Dadák, 1983). The average Pearson coefficient value obtained was respectively 0.94 and 0.95 for $R-/ L D L+$ and $R+/ L D L+$ series. No specific labeling was observed in other cytosolic organelles or plasma membrane. For images obtained with Lysotracker Red ${ }^{\oplus}$ (data not shown), the Pearson coefficient values obtained were much lower in all cases (0.2-0.3). No significant amounts of berberine have been evidenced in lysosomes (even for the LDL+ series at the shorter incubation times) although the LDL clearly play a role in the uptake of berberine, especially for the $R+/ L D L+$ series. Taken together, our results show that LDL play a role in the cellular incorporation of the berberine, but have only a marginal effect on its intracellular behavior. This indicates a fast redistribution of the berberine in favor of mitochondria due to its release from LDL or its escape from early endocytosis compartments, during the first 15 minutes. Such behavior, leading to a specific mitochondrial accumulation, is almost classical for hydrophobic compound bearing cationic charges (Kessel et al., 2011, 2003; Ma et al., 2013; Rodriguez et al., 2009).

\section{5- Evaluation of the photo-induced effects on U87-MG cells.}

The level of lipid oxidation in all the experiment series has been assessed by the dosage of malondialdehyde (MDA), a secondary product of lipid peroxidation reactions (Figures 6A-D). The photocytotoxic activity of the berberine is clearly evidenced by the light-dependent MDA production in all series in comparison with the control cells. This photooxidation increases with the light-dose. For R-series, no significant differences are induced by the LDLpreloading of the berberine. For $\mathrm{R}+$ series, in contrast, the MDA production is significantly increased by the LDL-delivery for high light doses $\left(50\right.$ and $\left.100 \mathrm{~J} / \mathrm{cm}^{2}\right)$. This observation is in good accordance with the fact that LDL play a role in the uptake of berberine, even if the trend to increased uptake is certainly not sufficient to explain such an increase of photocytotoxicity. However, due to the potentially different pathways, free and LDLpreloaded berberine molecules could not have similar molecular targets ${ }^{28}$ and other components such as proteins can also be oxidized.

The photo-induced potential of free and LDL-associated berberine as antiproliferative agents has been tested. In all the experiment series, the cellular viability was assessed using MTT assay (Figure 6E-F). Both forms of berberine significantly decreased the glioma cells viability in comparison to control treatments. In both culture conditions, cell death is light-dosedependent. However, as expected, cell viability was significantly more affected for R+/LDL+ cells. Altogether, our "upon irradiation" results show that the decrease of the viability of 
berberine-photosensitized cells is directly correlated to the lipid peroxidation level that appears to be well correlated to the berberine intracellular accumulation level.

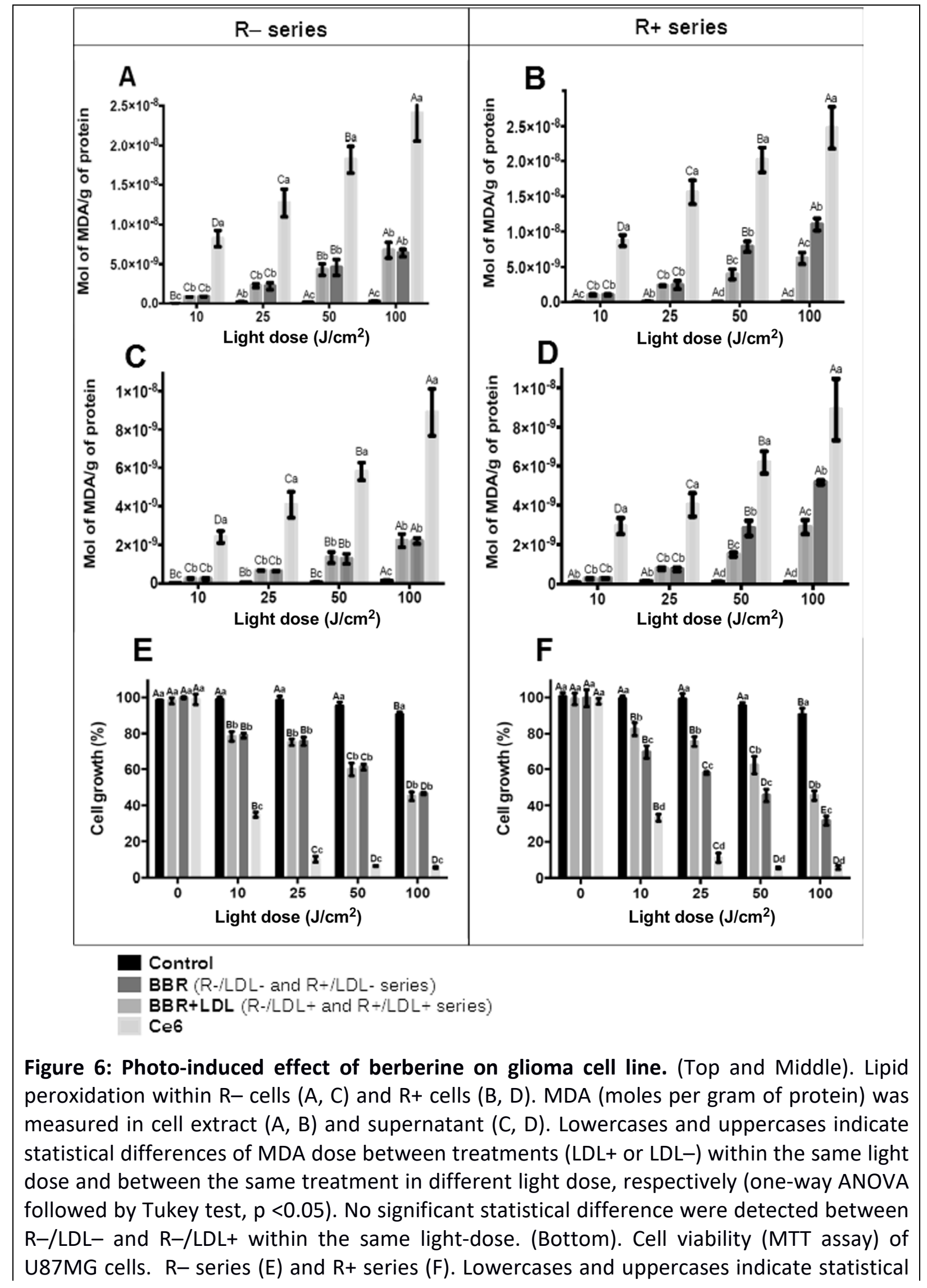


differences of cell viability between treatments within the same light-dose and between the same treatment in different light-dose, respectively (one-way ANOVA followed by Tukey test, $\mathrm{p}<0.05)$.

\section{4- Conclusions}

Berberine presents a wide range of pharmacological applications and has driven an increasing interest, in particular for application in anticancer therapy. In this context, the present study gives insights into the role of LDL particles as natural nano-carriers of this compound. First, the binding of the berberine is important, corresponding to the fixation of 400 berberine molecules per LDL with high affinity. At physiologically relevant LDL concentration $\left(7 \times 10^{-6} \mathrm{M}\right)$, the ratio of associated berberine is $99.9 \%$, what underlie the importance of their role evidenced in this work. Moreover, due to the capability of the LDL particles to cross the blood-brain barrier (Candela et al., 2008), this very high affinity suggests that the association of berberine to these lipoproteins can be involved in the berberine ability to penetrate this barrier and exhibit therapeutic potential for central nervous system disorders (Kulkarni and Dhir, 2010; Lin et al., 2013). Second, this association involves the apoprotein B100 or, most likely, its vicinity. However, the recognition of LDL by their cellular receptor is shown to be unaltered upon the binding of berberine. This suggests that the interaction is not likely to involve the outer domain of the apoprotein, as previously shown for other photosensitizers (Bonneau et al., 2007, 2002). As a matter of fact, LDL are able to increase the uptake of berberine by cells and LDL delivery of berberine allows a more specific targeting of cells characterized by a high level of B/E receptors such as in tumor cells. Moreover, delivered by LDL or not, the subcellular localization of berberine remains unchanged, in mitochondria. This may indicate a release of the drug from LDL after cellular binding or a subcellular redistribution after the cellular internalization. This point has to be taken into consideration with regards to the possible degradation of certain photosensitizers in lysosomes after endocytosis and their subsequent lack of activity. Moreover, the mitochondria are important targets in photodynamic therapy and many other hydrophobic cationic compounds have been designed to present such a behavior leading to this subcellular localization (Kessel et al., 2011, 2003; Rodriguez et al., 2009). This point is well correlated with our results showing an increased photo-oxidation and a photo-induced decreased of glioma cell viability mediated by the LDL-preloaded berberine when targeted cells over-express receptor $B / E$.

In summary, our results show the potential of berberine as a photosensitizing agent for PDT applications, in particular due to their behavior towards LDL as plasma vehicles. In this regard other studies are being conducted in order to precise the mechanism of cell death photo-activated by berberine once delivered by LDL.

\section{Acknowledgements}

This work was funded by Fundação de Amparo à Pesquisa do Estado de São Paulo (FAPESPBrasil, grant 2011/23031-3). N.L.A. thanks Fundação de Amparo à Pesquisa do Estado de São Paulo (FAPESP-Brasil) for student fellowship.

\section{References}


Acherar, S., Colombeau, L., Frochot, C., Vanderesse, R., 2015. Synthesis of Porphyrin, Chlorin and Phthalocyanine Derivatives by Azide-Alkyne Click Chemistry. Curr. Med. Chem. 22, 3217-3254.

Azzouzi, A.-R., Barret, E., Moore, C.M., Villers, A., Allen, C., Scherz, A., Muir, G., de Wildt, M., Barber, N.J., Lebdai, S., Emberton, M., 2013. TOOKAD $\left({ }^{\circledR}\right)$ Soluble vascular-targeted photodynamic (VTP) therapy: determination of optimal treatment conditions and assessment of effects in patients with localised prostate cancer. BJU Int. 112, 766774. doi:10.1111/bju.12265

Beck, T.J., Kreth, F.W., Beyer, W., Mehrkens, J.H., Obermeier, A., Stepp, H., Stummer, W., Baumgartner, R., 2007. Interstitial photodynamic therapy of nonresectable malignant glioma recurrences using 5-aminolevulinic acid induced protoporphyrin IX. Lasers Surg. Med. 39, 386-393. doi:10.1002/Ism.20507

Bonneau, S., Morlière, P., Brault, D., 2004. Dynamics of interactions of photosensitizers with lipoproteins and membrane-models: correlation with cellular incorporation and subcellular distribution. Biochem. Pharmacol. 68, 1443-1452. doi:10.1016/j.bcp.2004.06.014

Bonneau, S., Vever-Bizet, C., 2008. Tetrapyrrole photosensitisers, determinants of subcellular localisation and mechanisms of photodynamic processes in therapeutic approaches. Expert Opin. Ther. Pat. 18, 1011-1025. doi:10.1517/13543776.18.9.1011

Bonneau, S., Vever-Bizet, C., Mojzisova, H., Brault, D., 2007. Tetrapyrrole-photosensitizers vectorization and plasma LDL: a physico-chemical approach. Int. J. Pharm. 344, 7887. doi:10.1016/j.ijpharm.2007.06.019

Bonneau, S., Vever-Bizet, C., Morlière, P., Mazière, J.-C., Brault, D., 2002. Equilibrium and kinetic studies of the interactions of a porphyrin with low-density lipoproteins. Biophys. J. 83, 3470-3481. doi:10.1016/S0006-3495(02)75346-0

Boyle, R.W., Dolphin, D., 1996. Structure and biodistribution relationships of photodynamic sensitizers. Photochem. Photobiol. 64, 469-485.

Candela, P., Gosselet, F., Miller, F., Buee-Scherrer, V., Torpier, G., Cecchelli, R., Fenart, L., 2008. Physiological pathway for low-density lipoproteins across the blood-brain barrier: transcytosis through brain capillary endothelial cells in vitro. Endothel. J. Endothel. Cell Res. 15, 254-264. doi:10.1080/10623320802487759

Castano, A.P., Demidova, T.N., Hamblin, M.R., 2004. Mechanisms in photodynamic therapy: part one--photosensitizers, photochemistry and cellular localization. Photodiagnosis Photodyn. Ther. 1, 279-293. doi:10.1016/S1572-1000(05)00007-4

Cheng, L., Wang, M., Zhao, P., Zhu, H., Zhu, R., Sun, X., Yao, S., Wang, S., 2009. The examination of berberine excited state by laser flash photolysis. Spectrochim. Acta. A. Mol. Biomol. Spectrosc. 73, 268-272. doi:10.1016/j.saa.2009.02.008

Cheng, L.-L., Wang, M., Zhu, H., Li, K., Zhu, R.-R., Sun, X.-Y., Yao, S.-D., Wu, Q.-S., Wang, S.-L., 2009. Characterization of the transient species generated by the photoionization of Berberine: a laser flash photolysis study. Spectrochim. Acta. A. Mol. Biomol. Spectrosc. 73, 955-959. doi:10.1016/j.saa.2009.05.001

Du, K.L., Both, S., Friedberg, J.S., Rengan, R., Hahn, S.M., Cengel, K.A., 2010. Extrapleural pneumonectomy, photodynamic therapy and intensity modulated radiation therapy for the treatment of malignant pleural mesothelioma. Cancer Biol. Ther. 10, 425-429.

Gu, Y., Zhang, Y., Shi, X., Li, X., Hong, J., Chen, J., Gu, W., Lu, X., Xu, G., Ning, G., 2010. Effect of traditional Chinese medicine berberine on type 2 diabetes based on 
comprehensive metabonomics. Talanta 81, 766-772. doi:10.1016/j.talanta.2010.01.015

Halfman, C.J., Nishida, T., 1972. Method for measuring the binding of small molecules to proteins from binding-induced alterations of physical-chemical properties. Biochemistry (Mosc.) 11, 3493-3498.

Hsieh, Y.-J., Wu, C.-C., Chang, C.-J., Yu, J.-S., 2003. Subcellular localization of Photofrin determines the death phenotype of human epidermoid carcinoma A431 cells triggered by photodynamic therapy: when plasma membranes are the main targets. J. Cell. Physiol. 194, 363-375. doi:10.1002/jcp.10273

Hsieh, Y.-J., Yu, J.-S., Lyu, P.-C., 2010. Characterization of photodynamic therapy responses elicited in A431 cells containing intracellular organelle-localized photofrin. J. Cell. Biochem. 111, 821-833. doi:10.1002/jcb.22767

Hu, Y.-J., Ou-Yang, Y., Dai, C.-M., Liu, Y., Xiao, X.-H., 2010. Binding of berberine to bovine serum albumin: spectroscopic approach. Mol. Biol. Rep. 37, 3827-3832. doi:10.1007/s11033-010-0038-x

Huntosova, V., Alvarez, L., Bryndzova, L., Nadova, Z., Jancura, D., Buriankova, L., Bonneau, S., Brault, D., Miskovsky, P., Sureau, F., 2010. Interaction dynamics of hypericin with low-density lipoproteins and U87-MG cells. Int. J. Pharm. 389, 32-40. doi:10.1016/j.ijpharm.2010.01.010

Inbaraj, J.J., Kukielczak, B.M., Bilski, P., Sandvik, S.L., Chignell, C.F., 2001. Photochemistry and Photocytotoxicity of Alkaloids from Goldenseal (Hydrastis canadensis L.) 1. Berberine. Chem. Res. Toxicol. 14, 1529-1534. doi:10.1021/tx0155247

Jantová, S., Letasiová, S., Brezová, V., Cipák, L. 'ubos, Lábaj, J., 2006. Photochemical and phototoxic activity of berberine on murine fibroblast NIH-3T3 and Ehrlich ascites carcinoma cells. J. Photochem. Photobiol. B 85, 163-176. doi:10.1016/j.jphotobiol.2006.07.001

Jayaram, D.T., Ramos-Romero, S., Shankar, B.H., Garrido, C., Rubio, N., Sanchez-Cid, L., Gómez, S.B., Blanco, J., Ramaiah, D., 2016. In Vitro and in Vivo Demonstration of Photodynamic Activity and Cytoplasm Imaging through TPE Nanoparticles. ACS Chem. Biol. 11, 104-112. doi:10.1021/acschembio.5b00537

Kerdous, R., Heuvingh, J., Bonneau, S., 2011. Photo-dynamic induction of oxidative stress within cholesterol-containing membranes: Shape transitions and permeabilization. Biochim. Biophys. Acta BBA - Biomembr. 1808, 2965-2972. doi:10.1016/j.bbamem.2011.08.002

Kessel, D., Luguya, R., Vicente, M.G.H., 2003. Localization and photodynamic efficacy of two cationic porphyrins varying in charge distributions. Photochem. Photobiol. 78, 431435.

Kessel, D., Luo, Y., Deng, Y., Chang, C.K., 1997. The role of subcellular localization in initiation of apoptosis by photodynamic therapy. Photochem. Photobiol. 65, 422-426.

Kessel, D., Price, M., Caruso, J., Reiners, J., 2011. Effects of photodynamic therapy on the endocytic pathway. Photochem. Photobiol. Sci. Off. J. Eur. Photochem. Assoc. Eur. Soc. Photobiol. 10, 491-498. doi:10.1039/c0pp00276c

Kuimova, M.K., Yahioglu, G., Ogilby, P.R., 2009. Singlet Oxygen in a Cell: Spatially Dependent Lifetimes and Quenching Rate Constants. J. Am. Chem. Soc. 131, 332-340. doi:10.1021/ja807484b

Kulkarni, S.K., Dhir, A., 2010. Berberine: a plant alkaloid with therapeutic potential for central nervous system disorders. Phytother. Res. PTR 24, 317-324. doi:10.1002/ptr.2968 
Kuo, C.-L., Chi, C.-W., Liu, T.-Y., 2004. The anti-inflammatory potential of berberine in vitro and in vivo. Cancer Lett. 203, 127-137.

Küpeli, E., Koşar, M., Yeşilada, E., Hüsnü, K., Başer, C., 2002. A comparative study on the antiinflammatory, antinociceptive and antipyretic effects of isoquinoline alkaloids from the roots of Turkish Berberis species. Life Sci. 72, 645-657.

Kuzelova, K., Brault, D., 1994. Kinetic and equilibrium studies of porphyrin interactions with unilamellar lipidic vesicles. Biochemistry (Mosc.) 33, 9447-9459. doi:10.1021/bi00198a010

Lakowicz, J.R. (Ed.), 2006. Principles of Fluorescence Spectroscopy. Springer US, Boston, MA.

Lin, T.-Y., Lin, Y.-W., Lu, C.-W., Huang, S.-K., Wang, S.-J., 2013. Berberine Inhibits the Release of Glutamate in Nerve Terminals from Rat Cerebral Cortex. PLoS ONE 8, e67215. doi:10.1371/journal.pone.0067215

Ma, X., Zhou, J., Zhang, C.-X., Li, X.-Y., Li, N., Ju, R.-J., Shi, J.-F., Sun, M.-G., Zhao, W.-Y., Mu, L.M., Yan, Y., Lu, W.-L., 2013. Modulation of drug-resistant membrane and apoptosis proteins of breast cancer stem cells by targeting berberine liposomes. Biomaterials 34, 4452-4465. doi:10.1016/j.biomaterials.2013.02.066

Mikes, V., Dadák, V., 1983. Berberine derivatives as cationic fluorescent probes for the investigation of the energized state of mitochondria. Biochim. Biophys. Acta 723, 231-239.

Moan, J., Berg, K., 1991. The Photodegradation of Porphyrins in Cells Can Be Used to Estimate the Lifetime of Singlet Oxygen. Photochem. Photobiol. 53, 549-553. doi:10.1111/j.1751-1097.1991.tb03669.x

Mojzisova, H., Bonneau, S., Maillard, P., Berg, K., Brault, D., 2009. Photosensitizing properties of chlorins in solution and in membrane-mimicking systems. Photochem. Photobiol. Sci. Off. J. Eur. Photochem. Assoc. Eur. Soc. Photobiol. 8, 778-787. doi:10.1039/b822269j

Mojzisova, H., Bonneau, S., Vever-Bizet, C., Brault, D., 2007. Cellular uptake and subcellular distribution of chlorin e 6 as functions of $\mathrm{pH}$ and interactions with membranes and lipoproteins. Biochim. Biophys. Acta 1768, 2748-2756. doi:10.1016/j.bbamem.2007.07.002

Pariser, D.M., Lowe, N.J., Stewart, D.M., Jarratt, M.T., Lucky, A.W., Pariser, R.J., Yamauchi, P.S., 2003. Photodynamic therapy with topical methyl aminolevulinate for actinic keratosis: results of a prospective randomized multicenter trial. J. Am. Acad. Dermatol. 48, 227-232. doi:10.1067/mjd.2003.49

Peng, K.-W., Wang, H., Qin, Z., Wijewickrama, G.T., Lu, M., Wang, Z., Bolton, J.L., Thatcher, G.R.J., 2009. Selective estrogen receptor modulator delivery of quinone warheads to DNA triggering apoptosis in breast cancer cells. ACS Chem. Biol. 4, 1039-1049. doi:10.1021/cb9001848

Piette, J., Volanti, C., Vantieghem, A., Matroule, J.-Y., Habraken, Y., Agostinis, P., 2003. Cell death and growth arrest in response to photodynamic therapy with membranebound photosensitizers. Biochem. Pharmacol. 66, 1651-1659.

Remppis, A., Bea, F., Greten, H.J., Buttler, A., Wang, H., Zhou, Q., Preusch, M.R., Enk, R., Ehehalt, R., Katus, H., Blessing, E., 2010. Rhizoma Coptidis inhibits LPS-induced MCP$1 /$ CCL2 production in murine macrophages via an AP-1 and NFkappaB-dependent pathway. Mediators Inflamm. 2010, 194896. doi:10.1155/2010/194896

Rodriguez, M.E., Zhang, P., Azizuddin, K., Delos Santos, G.B., Chiu, S., Xue, L., Berlin, J.C., Peng, X., Wu, H., Lam, M., Nieminen, A.-L., Kenney, M.E., Oleinick, N.L., 2009. 
Structural factors and mechanisms underlying the improved photodynamic cell killing with silicon phthalocyanine photosensitizers directed to lysosomes versus mitochondria. Photochem. Photobiol. 85, 1189-1200. doi:10.1111/j.17511097.2009.00558.x

Sarna, L.K., Wu, N., Hwang, S.-Y., Siow, Y.L., O, K., 2010. Berberine inhibits NADPH oxidase mediated superoxide anion production in macrophages. Can. J. Physiol. Pharmacol. 88, 369-378. doi:10.1139/Y09-136

Silva, A.K.A., Kolosnjaj-Tabi, J., Bonneau, S., Marangon, I., Boggetto, N., Aubertin, K., Clément, O., Bureau, M.F., Luciani, N., Gazeau, F., Wilhelm, C., 2013. Magnetic and photoresponsive theranosomes: translating cell-released vesicles into smart nanovectors for cancer therapy. ACS Nano 7, 4954-4966. doi:10.1021/nn400269x

Vuddanda, P.R., Chakraborty, S., Singh, S., 2010. Berberine: a potential phytochemical with multispectrum therapeutic activities. Expert Opin. Investig. Drugs 19, 1297-1307. doi:10.1517/13543784.2010.517745

Wang, Y.-X., Wang, Y.-P., Zhang, H., Kong, W.-J., Li, Y.-H., Liu, F., Gao, R.-M., Liu, T., Jiang, J.D., Song, D.-Q., 2009. Synthesis and biological evaluation of berberine analogues as novel up-regulators for both low-density-lipoprotein receptor and insulin receptor. Bioorg. Med. Chem. Lett. 19, 6004-6008. doi:10.1016/j.bmcl.2009.09.059

Woodburn, K.W., Vardaxis, N.J., Hill, J.S., Kaye, A.H., Reiss, J.A., Phillips, D.R., 1992. Evaluation of porphyrin characteristics required for photodynamic therapy. Photochem. Photobiol. 55, 697-704.

Wu, M., Wang, J., Liu, L., 2010. Advance of studies on anti-atherosclerosis mechanism of berberine. Chin. J. Integr. Med. 16, 188-192. doi:10.1007/s11655-010-0188-7

Yin, J., Xing, H., Ye, J., 2008. Efficacy of Berberine in Patients with Type 2 Diabetes. Metabolism. 57, 712-717. doi:10.1016/j.metabol.2008.01.013 
Figure S1: Berberine. (Left) Normalized absorption. (Right) fluorescence spectra in DMSO, ethanol (EtOH) and PBS. Spectra recorded at $1 \mu \mathrm{M}$. (Inset) Berberine molecular structure.
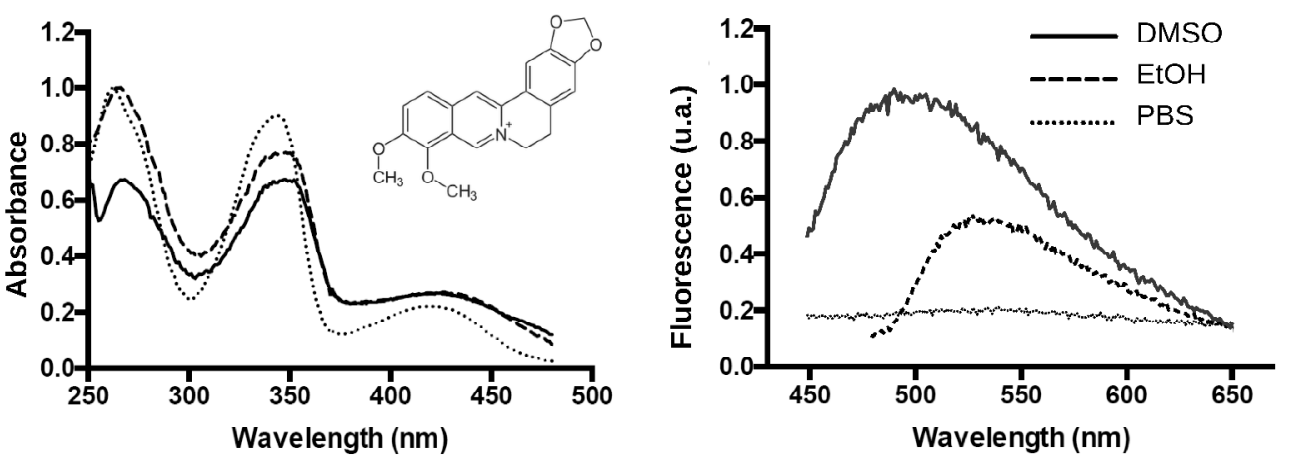

Table S1. Absorption and fluorescence data of berberine in different solvents

\begin{tabular}{|c|c|c|}
\hline Solvent & Absorption (nm) & Fluorescence (nm) \\
\hline DMSO & $434 \pm 2$ & $500 \pm 2$ \\
\hline Ethanol & $433 \pm 2$ & $520 \pm 2$ \\
\hline PBS & $416 \pm 2$ & $544 \pm 2$ \\
\hline
\end{tabular}

